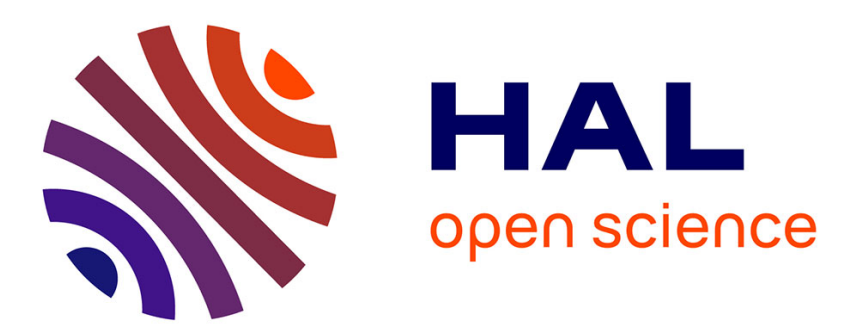

\title{
Towards the prediction of hydrothermal ageing of 3Y-TZP bioceramics from processing parameters
}

\author{
Chong Wei, Laurent Gremillard
}

\section{To cite this version:}

Chong Wei, Laurent Gremillard. Towards the prediction of hydrothermal ageing of 3YTZP bioceramics from processing parameters. Acta Materialia, 2018, 144, pp.245 - 256. 10.1016/j.actamat.2017.10.061 . hal-01758663

\section{HAL Id: hal-01758663 https://hal.science/hal-01758663}

Submitted on 5 Mar 2019

HAL is a multi-disciplinary open access archive for the deposit and dissemination of scientific research documents, whether they are published or not. The documents may come from teaching and research institutions in France or abroad, or from public or private research centers.
L'archive ouverte pluridisciplinaire HAL, est destinée au dépôt et à la diffusion de documents scientifiques de niveau recherche, publiés ou non, émanant des établissements d'enseignement et de recherche français ou étrangers, des laboratoires publics ou privés. 


\title{
Towards the prediction of hydrothermal ageing of 3Y-TZP bioceramics from processing parameters.
}

\author{
Published in Acta Materialia (2018) vol. 144, pp. 245-56, \\ https://doi.org/10.1016/j.actamat.2017.10.061
}

Chong Wei, Laurent Gremillard

Univ. Lyon, INSA-Lyon, MATEIS, UMR CNRS 5510, 7 Avenue Jean Capelle, 69621

Villeurbanne, France

\begin{abstract}
$\underline{\text { Abstract }}$
Hydrothermal ageing of yttria-stabilized tetragonal zirconia ceramics can have a strong influence on the lifetime of zirconia devices. Ageing kinetics are often described by the Mehl-Avrami-Johnson equation, most often used as a phenomenological description. This work seeks to relate the parameters of MAJ equations $\left(\mathrm{V}_{\max }, \mathrm{n}, \mathrm{b}_{0}\right.$ and $\mathrm{Q}$ ) to microstructural characteristics of the zirconia material: grain sizes, $\mathrm{Y}_{2} \mathrm{O}_{3}$ partitioning, monoclinic, tetragonal and cubic phases ratio. Samples with identical nominal composition of 3Y-TZP were prepared with grain sizes ranging from $190 \mathrm{~nm}$ to $773 \mathrm{~nm}$. From their microstructural parameters, a relationship between microstructural parameters and sintering cycles was first proposed, followed by a relationship between ageing parameters and microstructural parameters. These results provide a convenient framework to better develop the sintering cycle of zirconia biomaterial in order to maximize their resistance to hydrothermal ageing.
\end{abstract}

\section{Introduction}

Zirconia-based materials, especially yttria-stabilized tetragonal zirconia polycrystals (Y-TZP), exhibit the best mechanical properties of oxide ceramics: this is the consequence of phase transformation toughening, which increases its crack propagation resistance [1-3]. Furthermore, they are high-temperature resistant and offer low thermal conductivity, good ionic conductivity, good biocompatibility and superior aesthetic appearance [2]. Therefore YTZP ceramics are very attractive for a wide range of biomaterial applications such as fixedpartial denture in restorative dentistry or femoral heads in orthopedics [4,5]. Large efforts were already devoted to the study of mechanical properties of zirconia-based ceramics, but also of their sensitivity to low temperature degradation (LTD). Low-Temperature Degradation of zirconia (also called hydrothermal ageing) can be summarized as follows: the presence of water in the environment of zirconia pieces triggers the tetragonal to monoclinic $(\mathrm{t}-\mathrm{m})$ transformation of some grains on the surface, which potentially leads to roughening and micro-cracking because of the high volume increase $(\sim 5 \%)$ associated to the $\mathrm{t}-\mathrm{m}$ transformation. Hydrothermal ageing is driven by the annihilation of oxygen vacancies by water-derived species [6,7]. This process both destabilize the tetragonal phase and 
overstabilizes the monoclinic one [8]. Ageing kinetics are usually described by the MehlAvrami-Johnson equation [9] (eq. 1).

$\frac{V_{m}-V_{0}}{V_{\max }-V_{0}}=1-\exp \left(-(b . t)^{n}\right)$

In this equation, the parameter $\mathrm{b}$ is thermally activated: $b=b_{0} \exp \left(\frac{-Q}{R T}\right)$.

$\mathrm{V}_{\mathrm{m}}$ is the monoclinic phase content after ageing during a duration $t$ at absolute temperature $T$, $\mathrm{V}_{0}$ and $\mathrm{V}_{\max }$ are the initial and saturation levels of monoclinic phase content, and $\mathrm{R}$ is the ideal gas constant. $\mathrm{Q}$ is the activation energy, typically around $100 \mathrm{~kJ} / \mathrm{mol}$. The value of the parameter $n$ is typically between 0.3 and 3.5 [10].

Many factors such as different grain size, residual or applied stresses, density, content of $\mathrm{Y}_{2} \mathrm{O}_{3}$ in tetragonal phase, proportion of cubic phase, doping with more than one oxide, can influence the ageing process [4, 11-17]. A few examples of these influences are given below. Jansen et al. reported that doping with ceria or decreasing the grain size strongly improved the ageing resistance of Y-TZP [18]. For instance, 3Y-TZP ceramics with grain size lower than $100 \mathrm{~nm}$ exhibit almost no ageing, whereas submicrometric 3Y-TZP ceramics may undergo severe degradation under the same conditions [19]. A critical value of grain size around 300 $\mathrm{nm}$, below which ageing processes do not occur, was sometimes proposed [14], but later researches showed that this critical value has no physical basis [20] and may be dependent on other materials parameters [21]. Chevalier et al. reported that cubic grains are enriched by yttrium, which in turn leads to a decrease of the yttrium content in the neighboring tetragonal grains, making these Y-poor tetragonal grains more susceptible to transformation into monoclinic phase and thus affecting the ageing behavior of zirconia [12].

However, all the parameters mentioned above are interdependent, in particular through processing parameters: for instance, increasing the sintering time may increase both the grain size and the proportion of cubic phase [22], and the amount of cubic phase may also influence internal stresses. It is thus quite difficult to understand what parameters directly influence ageing [23]. Therefore, by carefully analyzing the microstructure and ageing behavior of several zirconia ceramics fabricated from the same powder, this paper seeks to isolate and quantify the influence of grain sizes, content of $\mathrm{Y}_{2} \mathrm{O}_{3}$ in tetragonal phase and amount of cubic phase on ageing kinetics parameters (Vmax, $\left.n, b_{0}, Q\right)$ of $3 Y-T Z P$.

\section{Materials and methods}

\subsection{Material preparation}

The samples were fabricated starting from Y-TZP powders (TZ3YE, Tosoh, Japan). TZ3YE contains $3 \mathrm{~mol} \%(5.2 \mathrm{wt} \%)$ yttria plus controlled alumina and silica doping. The zirconia green bodies used in the present study were prepared by slip casting. Firstly, the slurry were prepared by dispersing $150 \mathrm{~g}$ of TZ3YE powder in $37.5 \mathrm{~g} \mathrm{H}_{2} \mathrm{O}$, using $2.25 \mathrm{~g}$ Darvan $821 \mathrm{~A}$ as dispersant. Complete dispersion was achieved by ball milling with $150 \mathrm{~g}$ Y-TZP milling balls during 48 hours. The resulting slurries were then cast in porous plaster molds and dried in air at $25^{\circ} \mathrm{C}$ for 7 days. Finally the green bodies were sintered in a programmable electrical furnace, under different sintering conditions so as to obtain different microstructures: two materials were obtained by conventional sintering (samples $1430-2 \mathrm{~h}$ and $1430-5 \mathrm{~h}$ ); two other materials were obtained by two step sintering (conditions chosen to obtain fully dense materials with small grain size [24]: TSS1 and TSS2 materials); finally some series of samples obtained using the TSS2 sintering conditions were submitted to different post- 
sintering thermal treatment in order to modify their microstructure (materials PS1150-100h, PS1150-200h, PS1430-20h, PS1500-2h, PS1550-20h). The exact sintering cycles used for all materials are summarized in table 1. All samples (at least 6 per material) were shaped as 10x10 mm plates, polished, and annealed after polishing to remove any extra residual stress possibly induced by machining and polishing. The density of all samples was then measured by using Arthur's method, based on Archimede's principle.

Table 1: List of samples: processing hydrothermal ageing conditions; TSS stands for "Two Steps Sintering", PS for "Post Sintering" (post sintering heat treatment applied to TSS2 materials).

\begin{tabular}{|c|c|c|c|c|}
\hline Sample & sintering condition & $\begin{array}{l}\text { annealing } \\
\text { conditions }\end{array}$ & $\begin{array}{l}\text { aging } \\
\text { temperature } /{ }^{\circ} \mathrm{C}\end{array}$ & density \\
\hline TSS1 & $\mathrm{T} 11300^{\circ} \mathrm{C}$ T2 $1150^{\circ} \mathrm{C}-15 \mathrm{~h}$ & $1150^{\circ} \mathrm{C}-1 \mathrm{~h}$ & $85,110,134,140$ & 6.04 \\
\hline TSS2 & $\mathrm{T} 11280^{\circ} \mathrm{C} \mathrm{T} 21150^{\circ} \mathrm{C}-25 \mathrm{~h}$ & $1150^{\circ} \mathrm{C}-1 \mathrm{~h}$ & $85,110,134,140$ & 6.07 \\
\hline $1430-2 h$ & $1430^{\circ} \mathrm{C}-2 \mathrm{~h}$ & $1250^{\circ} \mathrm{C}-0.5 \mathrm{~h}$ & $85,110,134,140$ & 6.05 \\
\hline 1430-5h & $1430^{\circ} \mathrm{C}-5 \mathrm{~h}$ & $1250^{\circ} \mathrm{C}-0.5 \mathrm{~h}$ & $85,110,134,140$ & 6.04 \\
\hline PS1150-100h & $\begin{array}{l}\text { TSS2+post sintering } 1150^{\circ} \mathrm{C} \text { - } \\
100 \mathrm{~h}\end{array}$ & & $\begin{array}{l}134+\text { stepwise } \\
\text { procedure }\end{array}$ & 6.07 \\
\hline PS1150-200h & $\begin{array}{l}\text { TSS } 2+\text { post sintering } 1150^{\circ} \mathrm{C}- \\
200 \mathrm{~h}\end{array}$ & & $\begin{array}{l}134+\text { stepwise } \\
\text { procedure }\end{array}$ & 6.07 \\
\hline PS1430-20h & TSS2+post sintering $1430^{\circ} \mathrm{C}-20 \mathrm{~h}$ & & $\begin{array}{l}134+\text { stepwise } \\
\text { procedure }\end{array}$ & 6.07 \\
\hline PS1500-2h & $\mathrm{TSS} 2+$ post sintering $1500^{\circ} \mathrm{C}-2 \mathrm{~h}$ & & $\begin{array}{l}134+\text { stepwise } \\
\text { procedure }\end{array}$ & 6.07 \\
\hline PS1550-20h & TSS $2+$ post sintering $1550^{\circ} \mathrm{C}-2 \mathrm{~h}$ & & $\begin{array}{l}134+\text { stepwise } \\
\text { procedure }\end{array}$ & 6.07 \\
\hline
\end{tabular}

\subsection{Microstructural analyses: grain size, proportion of cubic phase, yttria content}

SEM observations were conducted using a Zeiss Supra55 VP microscope. For each group of samples, grain size was obtained from micrographs taken on both side of 4 samples, using the linear intercept method, and multiplying by 1.56 the average linear intercept length of at least 500 grains to correct the fact that they were intercepted at random positions (not necessarily at their diameter) in accordance with the method developed by Mendelsohn et al. [25].

The average $\mathrm{Y}_{2} \mathrm{O}_{3}$ content in tetragonal phase and amount of cubic phase were obtained from XRD data (using a D8 Advance diffractometer, Bruker, Germany, with step size 0.02 deg and scan speed $1 \mathrm{~s} / \mathrm{step}$ ). To summarize, first a calibration curve of the amount of $\mathrm{Y}_{2} \mathrm{O}_{3}$ in the cubic and tetragonal phases versus the lattice parameters was established, from PDF files and previous work by other authors [26-28] (Fig.1). Then XRD patterns were recorded (on one sample per group) over a large angular range (15-120 deg. 20) and analyzed using an iterative procedure based on Rietveld refinement. Rietveld refinement was conducted with Topas 4.0 software (Bruker), using a fundamental parameters approach; only scale factors, lattice parameters, crystallite size and systematic diffractometer-related angular errors were set free during the refinements. The outcomes of the first iteration of Rietveld refinement were mainly the approximate proportions of the different phases (cubic and tetragonal) and the lattice parameters of the tetragonal phase (in most materials cubic peaks were lost in the background or convoluted with some tetragonal peaks). The amount of yttria in the tetragonal phase was then calculated from the calibration curve. Since the total amount of $\mathrm{Y}_{2} \mathrm{O}_{3}$ is known ( 3 mol.\%) from the composition of the powder, it was thus possible to determine the amount of yttria in the cubic phase (considering the approximate proportion of cubic phase) and thus its lattice parameter. The next iterations were conducted while setting the cubic 
phase lattice parameter as a constant (calculated from the amount of yttria in the cubic phase), which allowed evaluating more and more precise phases proportions and tetragonal phase lattice parameter, thus recalculating a more and more precise cubic phase lattice parameter. The iterations were continued until convergence ( 2 to 4 iterations generally allowed convergence to the $3^{\text {rd }}$ digit for the proportion of the phases and to the $6^{\text {th }}$ digit for the lattice parameters).

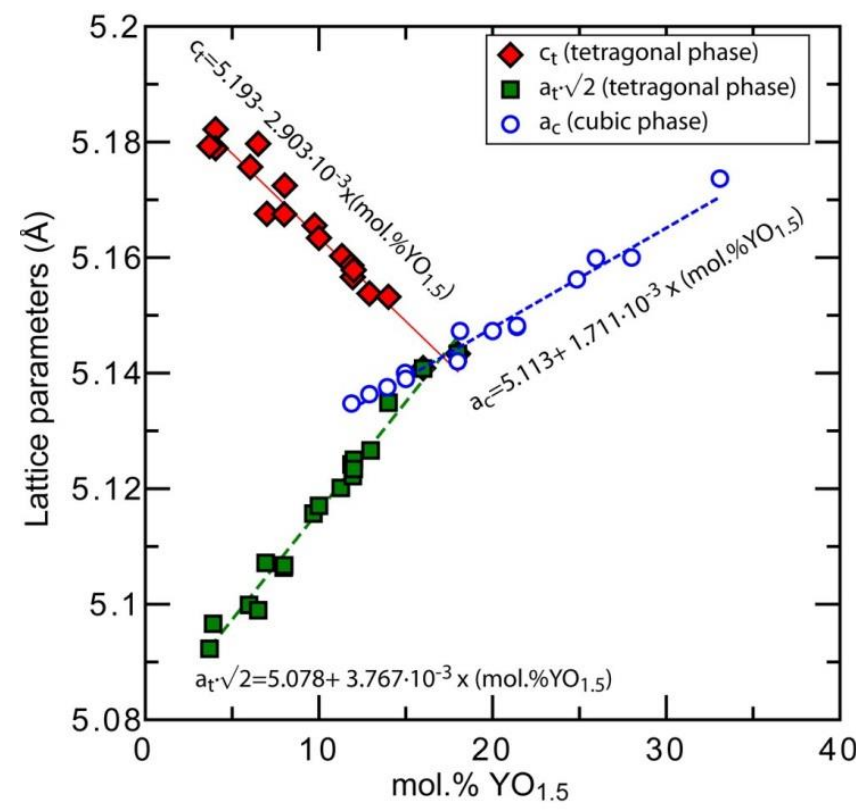

Figure 1: Calibration curve giving the lattice parameters of tetragonal and cubic zirconia vs yttrium amount.

\subsection{Assessment of ageing kinetics parameters.}

Ageing kinetics were evaluated by performing accelerated ageing tests on all samples in water vapour in an autoclave (Wolf Sanoclav), at temperatures ranging from 80 to $150^{\circ} \mathrm{C}$.

The amount of tetragonal to monoclinic phase transformation was measured at different time points by X-ray diffraction (XRD). XRD patterns were recorded in the $27-33^{\circ}(2 \theta)$ range with a scan speed of $0.2 \mathrm{deg} \cdot \mathrm{min}^{-1}$ and a step size of $0.05^{\circ}$, using a Bruker D8-advance diffractometer. The monoclinic $\mathrm{ZrO}_{2}$ phase content $\left(V_{m}\right)$ [29] was calculated as:

$$
V_{m}=\frac{1.311 X_{m}}{1+0.311 X_{m}}
$$

In which the value of $X_{m}$ was determined directly from the diffraction diagrams using Garvie and Nicholson's equation [30]:

$$
X_{m}=\frac{I_{m}^{-111}+I_{m}^{111}}{I_{m}^{-111}+I_{m}^{111}+I_{t}^{101}}
$$

Where $I_{p}^{h k l}$ is the area of the diffraction peak related to the (hkl) plane of phase $p$ ( $m$ for monoclinic and $t$ for tetragonal).

The hydrothermal ageing kinetics were rationalized by fitting the transformation curves with the Mehl-Avrami-Johnson laws [9] as explained in the introduction. For materials TSS1, 
TSS2, 1430-2h and 1430-5h, complete ageing kinetics were recorded at 140, 134, 110 and $85^{\circ} \mathrm{C}$ (one sample per temperature); then the ageing parameters $\left(\mathrm{V}_{0}, \mathrm{~V}_{\mathrm{m}}, \mathrm{b}_{0}, \mathrm{Q}, \mathrm{n}\right.$ ) were obtained using a fitting procedure consisting in minimizing the total quadratic error between the calculated kinetics and the experimental points.

In addition, stepwise ageing procedures [31] were designed as indicated in Table 2 in order to determine the values of Q, and $b_{0}$ for sample PS1150-200h, PS1430-20h, PS 1500-2h, PS1550-2h (for all these materials, a complete kinetics at $134^{\circ} \mathrm{C}$ was also performed). The stepwise procedure is based on ageing measurements at different temperature on a single sample, and can largely reduce the time necessary for correct extrapolations. Following this procedure, PS1430-20h, PS 1500-2h and PS1550-2h materials (2 samples each) were aged between $80^{\circ} \mathrm{C}$ and $134^{\circ} \mathrm{C}$; due to much slower ageing kinetics, PS1150-200h material (2 samples) was aged using a specific stepwise procedure, between $80^{\circ} \mathrm{C}$ and $150^{\circ} \mathrm{C}$.

Table 2: Stepwise ageing procedure for PS1150-200h, PS1430-20h, PS 1500-2h, PS1550-2h; the procedure for PS1150-200h involves much longer ageing duration because ageing of PS1150-200h is much slower than for other materials.

\begin{tabular}{cc|cc}
\hline \multicolumn{2}{c|}{ PS1150-200h } & \multicolumn{2}{|c}{$\begin{array}{c}\text { PS1430-20h,PS 1500-2h, } \\
\text { PS1550-2h }\end{array}$} \\
$\mathbf{T}_{\mathbf{i}}\left({ }^{\circ} \mathbf{C}\right)$ & $\Delta \mathbf{t}_{\mathbf{i}}(\mathbf{h})$ & $\mathbf{T}_{\mathbf{i}}\left({ }^{\circ} \mathbf{C}\right)$ & $\Delta \mathbf{t}_{\mathbf{i}}(\mathbf{h})$ \\
\hline 150 & 26 & 134 & 2 \\
141 & 20 & 141 & 2 \\
110 & 100 & 110 & 30 \\
121 & 50 & 121 & 18 \\
134 & 25 & 100 & 75 \\
100 & 145 & 90 & 178 \\
90 & 267 & 80 & 265 \\
80 & 259 & & \\
\hline
\end{tabular}

For the stepwise ageing procedure, equation (3) is used for initial assessment of the Q value, before an optimization procedure takes place to determine $\mathrm{V}_{0}, \mathrm{~V}_{\mathrm{m}}, \mathrm{b}_{0}, \mathrm{Q}$ and $\mathrm{n}$ (for detailed process, see reference [31]):

$$
\ln \left[\frac{1}{\Delta t_{i}} \ln \left(\frac{V_{\max }-V_{i-1}}{V_{\max }-V_{i}}\right)\right] \approx \ln \left(n b_{0}\right)-\frac{Q}{R T_{i}}
$$

\section{Results}

\section{$\underline{3.1 \text { Microstructural analyses }}$}

Density higher than $99 \%$ of the theoretical density (6.08) was achieved for all samples (density values are summarized in table 1). Fig.2 shows SEM micrographs of all the specimens. Even though they were manufactured using the same powder, due the different sintering thermal treatments the samples exhibit grain sizes ranging from 190 to $779 \mathrm{~nm}$. Very fine-grained zirconia ceramics were obtained by two step sintering, while materials with larger grains were obtained by conventional sintering. 

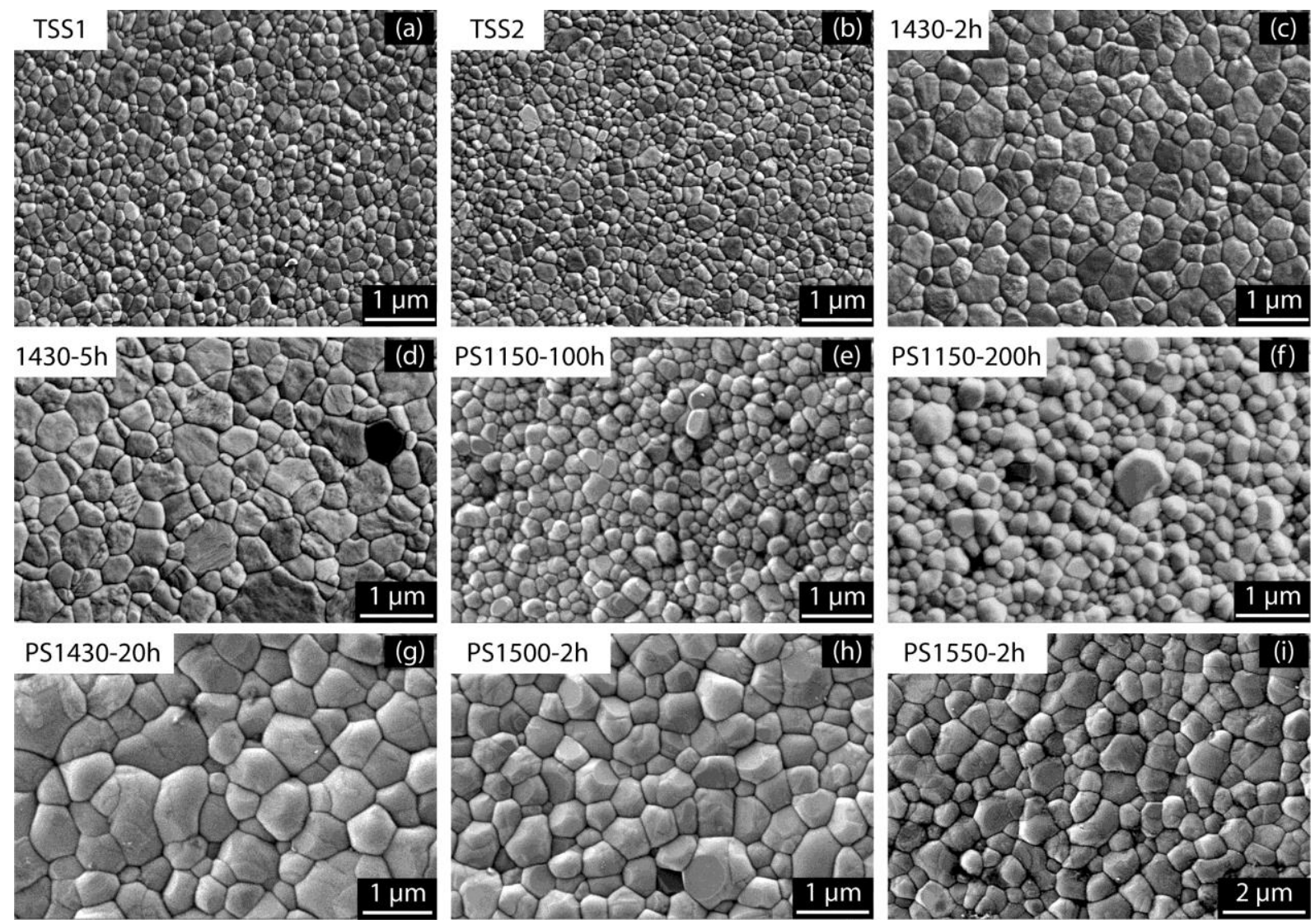

Figure 2: SEM micrographs of all specimens after annealing

The phase content and phase partitioning were analyzed by X-ray diffraction coupled to Rietveld analysis. The results of these microstructural analyses are shown in table 3 . Figure 3 illustrates the quantification of cubic phase by Rietveld analysis, on two extreme cases: the cubic peaks are hardly visible in TSS1 (that contain 10 wt.\% of cubic phase), while it's detectable "with the naked eye" on 1430-2h (18\% of cubic phase).

Table 3: Microstructural features of zirconia materials before aging

\begin{tabular}{ccccc}
\hline Sample & $\begin{array}{c}\text { wt.\% } \\
\text { cubic }\end{array}$ & $\begin{array}{c}\text { mol\% } \mathbf{Y}_{\mathbf{2}} \mathbf{O}_{\mathbf{3}} \\
\text { in tetragonal }\end{array}$ & $\begin{array}{c}\text { Grain size } \\
(\mathbf{n m})\end{array}$ & $\begin{array}{c}\mathbf{m o l \%} \mathbf{Y}_{\mathbf{2}} \mathbf{O}_{3} \text { in } \\
\text { cubic }\end{array}$ \\
\hline TSS1 & 0.107 & 2.90 & 210 & 3.84 \\
TSS2 & 0.117 & 2.87 & 190 & 3.97 \\
PS1150-100h & 0.151 & 2.58 & 290 & 5.33 \\
PS1150-200h & 0.175 & 2.34 & 320 & 6.16 \\
\hline PS1430-20h & 0.304 & 2.13 & 750 & 4.75 \\
1430-2h & 0.176 & 2.55 & 410 & 4.81 \\
1430-5h & 0.205 & 2.41 & 520 & 5.30 \\
PS1500-2h & 0.263 & 2.37 & 600 & 4.75 \\
PS1550-2h & 0.268 & 2.34 & 770 & 4.80 \\
\hline
\end{tabular}




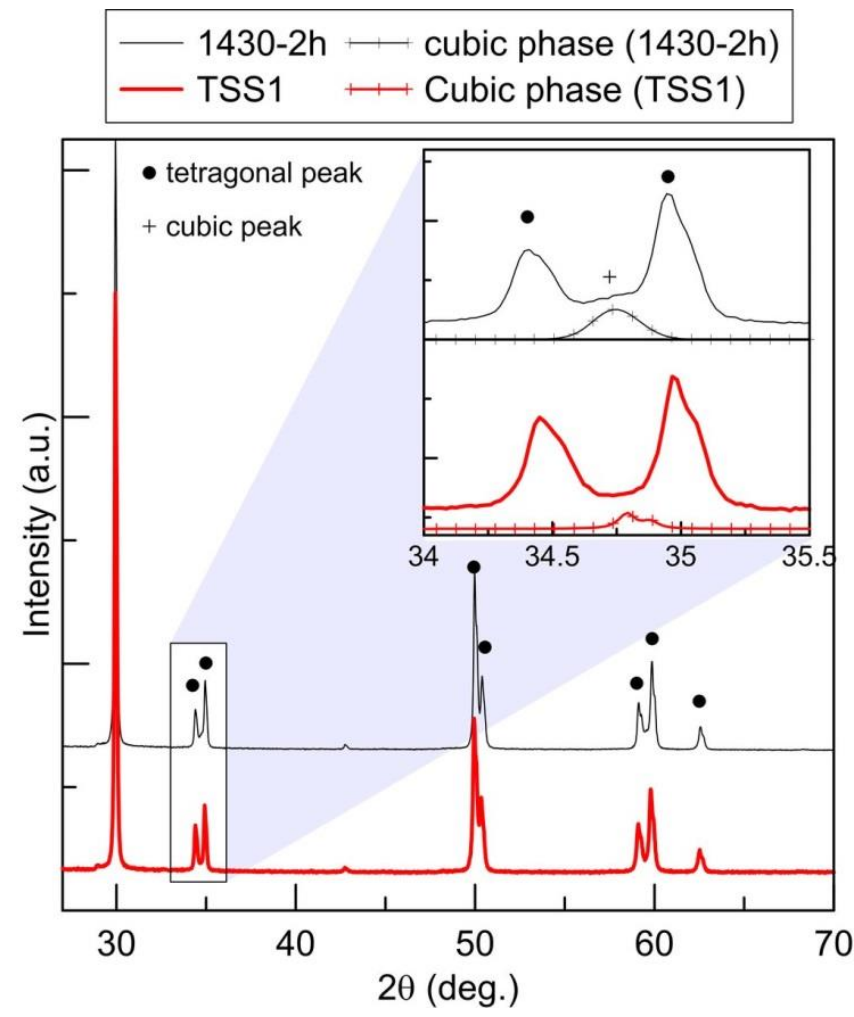

Figure 3: X-ray diffractograms of TSS1 (red, bold line) and 1430-2h (black, thin line); the inset shows a detail of the diagram around 35 deg. 2 : : tetragonal doublet around a cubic peak.

A few trends can be distinguished from these data. In particular, for a given sintering temperature (here, $1430^{\circ} \mathrm{C}$ or $1150^{\circ} \mathrm{C}$ ), the content of $\mathrm{Y}_{2} \mathrm{O}_{3}$ in tetragonal phase decreases linearly and the content of cubic phase increase linearly with increasing holding time (Fig.4); the variation are faster with increasing sintering temperature. Moreover, the grain size increases with increasing holding time.
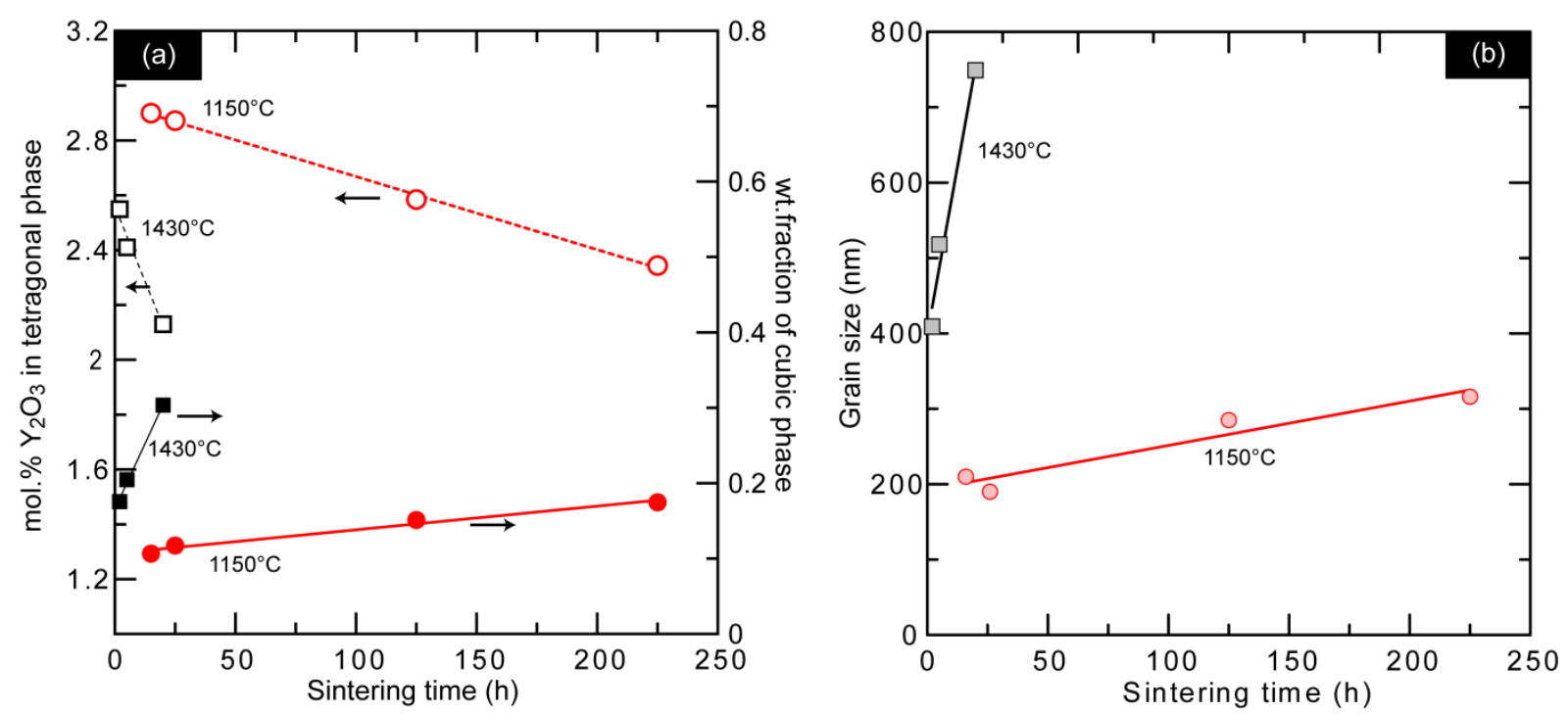

Figure 4: (a) $\mathrm{Y}_{2} \mathrm{O}_{3}$ content in tetragonal phase (open symbols), proportion of cubic phase (full symbols) and (b) grain size (light symbols) versus holding time for sintering cycles at $1430^{\circ} \mathrm{C}$ (squares) or $1150^{\circ} \mathrm{C}$ (discs). 
For identical holding times during sintering (here, 2 hours), the $\mathrm{Y}_{2} \mathrm{O}_{3}$ content in tetragonal phase decreases and the content of cubic phase increases with increasing sintering temperature (Fig. 5). In the same conditions, the grain size increases linearly with increasing sintering temperature (Fig. 5). Thus both higher sintering temperatures and longer dwell times can increase the grain size. Figure 4 shows that the grain size is much more sensitive to sintering temperature than to sintering time.

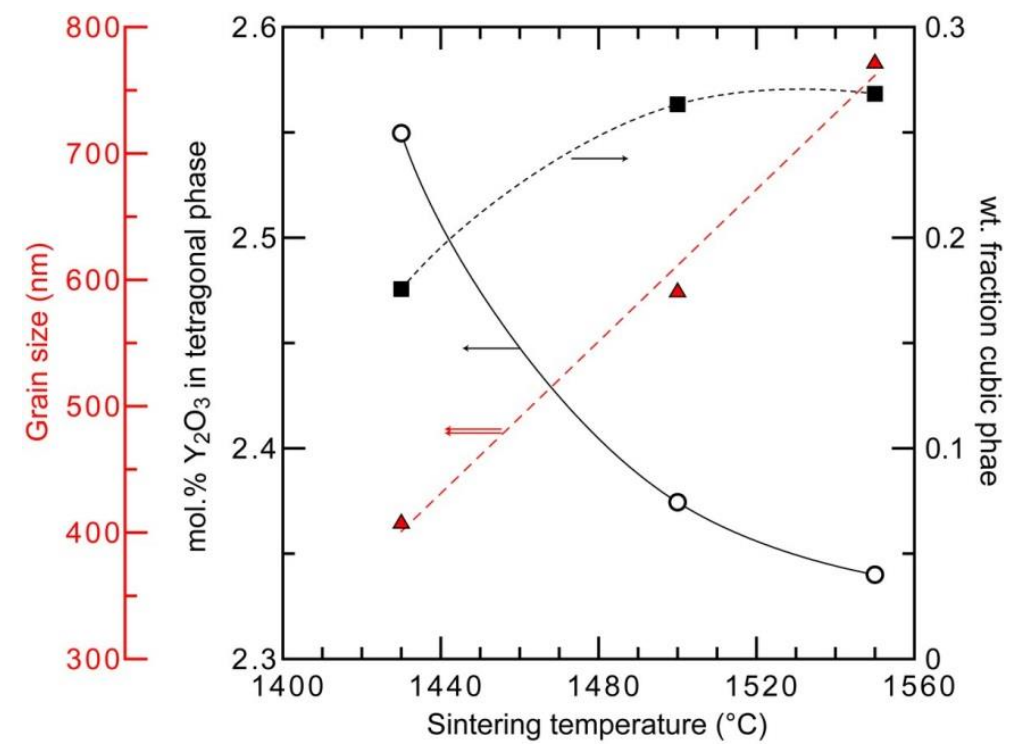

Figure 5: $\mathrm{Y}_{2} \mathrm{O}_{3}$ content in tetragonal phase (open circles), proportion of cubic phase (squares) and grain size (triangles) versus sintering temperature for a $2 \mathrm{~h}$ holding time during sintering.

Fig.6 illustrates the interdependence between grain size, proportion of cubic phase and Yttria content in the tetragonal phase. It shows that the grain size increases linearly with the proportion of cubic phase, while the $\mathrm{Y}_{2} \mathrm{O}_{3}$ content in tetragonal phase decreases linearly with increasing proportion of cubic phase. As a result, the $\mathrm{Y}_{2} \mathrm{O}_{3}$ content in tetragonal phase decreases when the grain size increases.

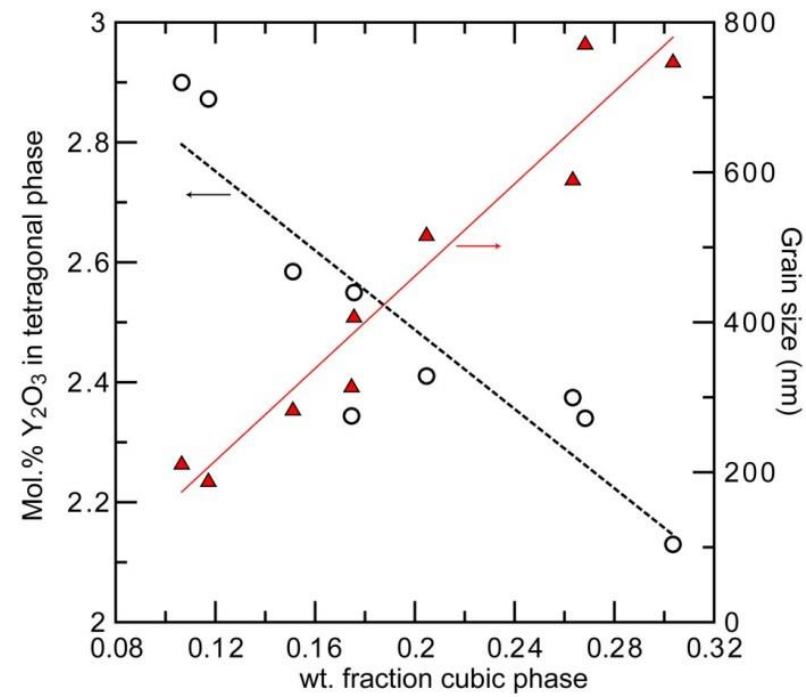

Figure 6: $\mathrm{Y}_{2} \mathrm{O}_{3}$ content in tetragonal phase (open circles) and grain size (triangles) versus the content of cubic phase. 


\subsection{Ageing kinetics}

TSS1 and TSS2 samples do not suffer from ageing, even after more than 2700 hours autoclave at $134^{\circ} \mathrm{C}, 1500$ hours at $140^{\circ} \mathrm{C}$ and 3000 hours at $90^{\circ} \mathrm{C}$.

The surface phase transformation curves for the other samples as a function of the hydrothermal ageing time are shown in Fig.7. The ageing kinetics measured at $134{ }^{\circ} \mathrm{C}$ are shown in Fig.8. PS1430-20h, PS1500-2h, PS1550-2h, 1430-2h and 1430-5h materials exhibit a similar ageing behavior, while PS1150-200h and PS1150-100h age much more slowly. These results are apparently coherent with the existence of a grain-size threshold $(\sim 300 \mathrm{~nm}$ [14]) under which hydrothermal ageing is not measurable using XRD.

The parameters of MAJ equation of the different samples were obtained using the procedure described in section 2.3, and reported in table 4. Unfortunately, these parameters could not be evaluated on PS1150-100h (this material ages too slowly: less than 10\% monoclinic phase after $3000 \mathrm{~h}$ ageing). For all materials considered here, the value of Vmax increases approximately linearly with increasing grain size and content of cubic phase and decreasing content of $\mathrm{Y}_{2} \mathrm{O}_{3}$ in tetragonal phase. The value of $\mathrm{n}$ decreases slightly with increasing grain size and content of cubic phase. When considering the values of $b_{0}$ and $Q$, two groups of samples can be distinguished: most materials show $\mathrm{b}_{0}$ around $10^{13}$ and $\mathrm{Q}$ around $115 \mathrm{~kJ} / \mathrm{mol}$, while PS1150-200h stands out with much lower values for both parameters $\left(b_{0}=8 \cdot 10^{2}\right.$ and $\mathrm{Q}=41 \mathrm{~kJ} / \mathrm{mol}$ ). As a result, PS1150-200h ages very slowly at $134^{\circ} \mathrm{C}$, but faster than all other samples at $37^{\circ} \mathrm{C}$ (fig. 8); this is obvious from the values of $\mathrm{b}$ at 134 and $37^{\circ} \mathrm{C}$ in table 4 . The knowledge of $\mathrm{Q}$ also allows to establish the time-temperature equivalence: $1 \mathrm{~h}$ in an autoclave at $134{ }^{\circ} \mathrm{C}$ represents around 5 years of hydrothermal ageing in vivo at $37^{\circ} \mathrm{C}$ for $1430-2 \mathrm{~h}, 1430$ 5h, PS1430-20h, PS1500-2h and PS1550-2h samples, but $44 \mathrm{~h}$ at $37^{\circ} \mathrm{C}$ for PS1150-200h samples. From Table 4 it can be determined that the 1430-5h sample has the best ageing resistance (lowest value of b) at $37^{\circ} \mathrm{C}$.

Table 4: Parameters of MAJ equation of the different materials

\begin{tabular}{lcccccc}
\hline \multicolumn{1}{c}{ samples } & Vmax & $\mathbf{n}$ & $\begin{array}{c}\mathbf{b}\left(\mathbf{1 3 4}^{\circ} \mathbf{C}\right) \\
\left(\mathbf{h}^{-\mathbf{1}}\right)\end{array}$ & $\begin{array}{c}\mathbf{b}\left(\mathbf{3 7}^{\circ} \mathbf{C}\right)\left(\mathbf{h}^{-}\right. \\
\mathbf{1})\end{array}$ & $\mathbf{b}_{\mathbf{0}}$ & $\begin{array}{c}\mathbf{Q} \\
(\mathbf{k J} / \mathbf{m o l})\end{array}$ \\
\hline $1430-2 \mathrm{~h}$ & 0.82 & 1.00 & $5.66 \cdot 10^{-2}$ & $1.19 \cdot 10^{-6}$ & $5.01 \cdot 10^{13}$ & 116.4 \\
$1430-5 \mathrm{~h}$ & 0.8 & 0.88 & $4.61 \cdot 10^{-2}$ & $1.07 \cdot 10^{-6}$ & $2.98 \cdot 10^{13}$ & 115.3 \\
PS1150-200h & 0.85 & 0.99 & $4.38 \cdot 10^{-3}$ & $1.00 \cdot 10^{-4}$ & $7.67 \cdot 10^{2}$ & 40.8 \\
PS1430-20h & 0.77 & 0.83 & $6.94 \cdot 10^{-2}$ & $1.42 \cdot 10^{-6}$ & $6.73 \cdot 10^{13}$ & 116.7 \\
PS1500-2h & 0.79 & 0.92 & $5.04 \cdot 10^{-2}$ & $1.13 \cdot 10^{-6}$ & $3.65 \cdot 10^{13}$ & 115.7 \\
PS1550-2h & 0.78 & 0.89 & $7.32 \cdot 10^{-2}$ & $2.18 \cdot 10^{-6}$ & $2.13 \cdot 10^{13}$ & 112.6 \\
\hline
\end{tabular}



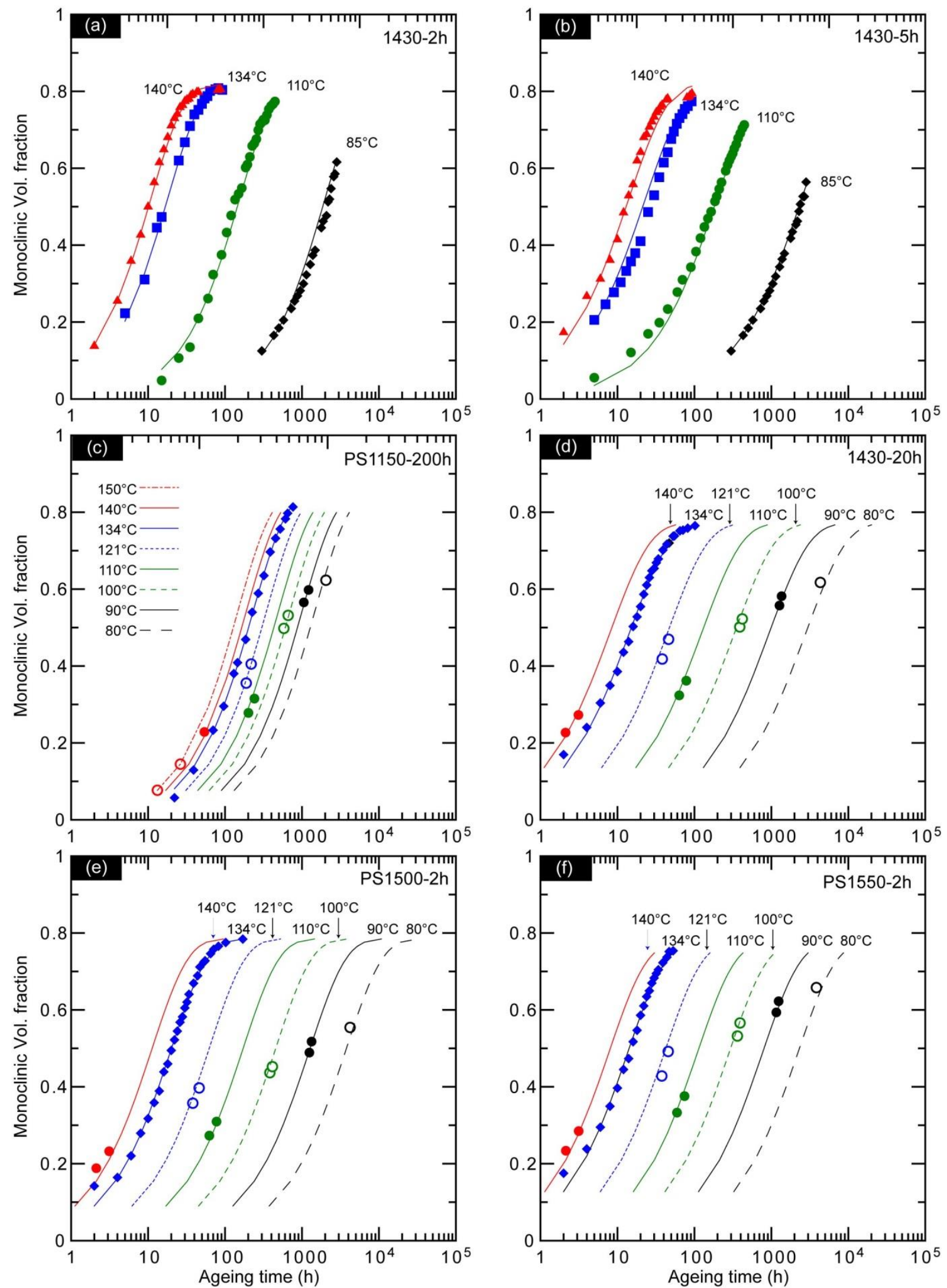

Figure 7: Hydrothermal ageing kinetics between 80 and $140^{\circ} \mathrm{C}$ for samples $1430-2 \mathrm{~h}(\mathrm{a}), 1430-5 \mathrm{~h}(\mathrm{~b})$, PS1150-200h(c), PS1430-20h (d), PS1500-2h (e), PS1550-2h (f). 


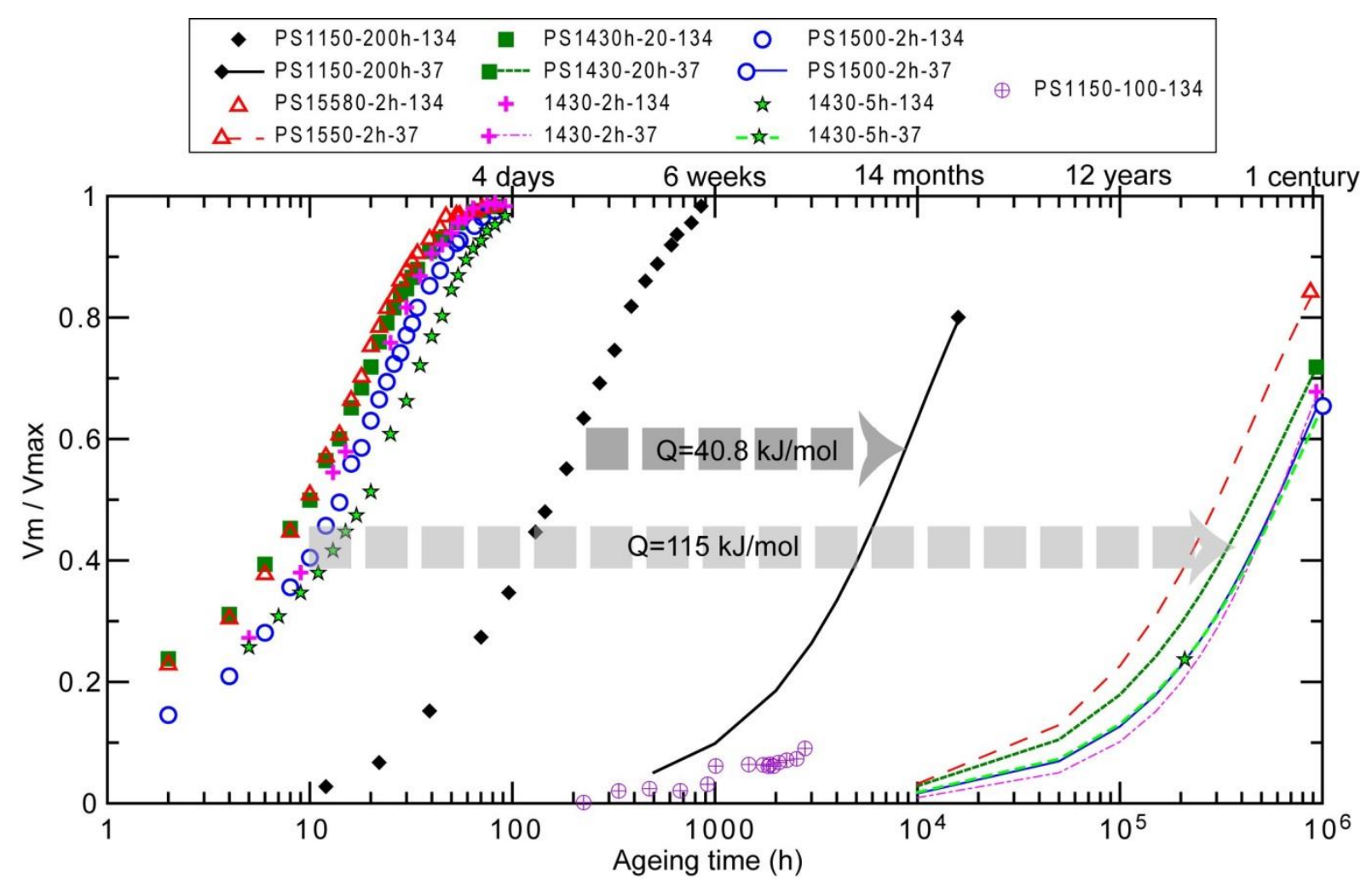

Figure 8: Ageing kinetics of all samples at $134^{\circ} \mathrm{C}$ (symbols) and $37^{\circ} \mathrm{C}$ (dotted lines).

\section{Discussion}

\subsection{Correlation analysis of structural parameters and sintering cycle}

In order to be able to better develop the sintering cycle, the results of this work can be combined to determine a relationship between structural parameters and sintering cycle. A few hypotheses can guide the choice of simple mathematical, phenomenological models for these relationships.

At constant temperature, the formation of cubic phase from tetragonal grains follows a nucleation and growth mechanism (nucleation being driven by Y diffusion [32]), thus can be described by a MAJ law (Eq. 4).

$f(T, t)=f_{0}+\left(f_{\max }-f_{0}\right)\left(1-\exp \left(-(c . t)^{n_{c}}\right)\right)$

In this equation, the parameter $\mathrm{c}$ is thermally activated: $c=c_{0} \exp \left(\frac{-Q_{c}}{R T}\right) ; f$ is the cubic phase content obtained after the sintering process during a duration $t$ at absolute temperature $T, f_{0}$ and $f_{\max }$ are the initial and saturation levels of cubic phase content, and $\mathrm{R}$ is the gas constant. $Q_{\mathrm{c}}$ is an apparent activation energy for the formation of cubic phase. Theoretically, $f_{\text {max }}$ could be calculated from the yttria-zirconia phase diagram $\left(f_{\max }\right.$ is determined by the temperature and the content of yttria). However, on the one hand this work involves rather complicated thermal treatments (two-step sintering and post-sintering annealing), and on the other hand after most thermal treatments the equilibrium phase partitioning may not be reached (thus the equilibrium phase diagram is not useful); thus it is easier and more correct to consider $f_{\max }$ as an adjustable parameter.

Assuming a homogeneous initial distribution of Yttrium, the Yttrium concentration in the tetragonal phase is directly controlled by the diffusion of $Y$ from the tetragonal phase to the 
grain boundaries and to the cubic phase [32]. Thus again a decreasing exponential law can be applied (eq. 5).

$y(T, t)=y_{0}-y_{d \max } \cdot\left(1-\exp \left(-(s . t)^{n_{y}}\right)\right)$

In this equation, the parameter $\mathrm{s}$ is thermally activated: $s=s_{0} \exp \left(\frac{-Q_{s}}{R T}\right) ; y$ is the content of $\mathrm{Y}_{2} \mathrm{O}_{3}$ in tetragonal phase during sintering process during a duration $t$ at absolute temperature $T, y_{0}$ is the initial content of $\mathrm{Y}_{2} \mathrm{O}_{3}$ in tetragonal phase, $y_{\mathrm{dmax}}$ are the maximum content of $\mathrm{Y}_{2} \mathrm{O}_{3}$ diffusing into the cubic phase, and $\mathrm{R}$ is the gas constant. $Q_{\mathrm{s}}$ is the apparent activation energy for yttrium diffusion.

Finally, since TZ3YE powder contains small amounts of alumina and silica that are mainly located at the grain boundaries as solute species, an equation of grain growth taking solute drag into account [33] can be used (Eq. 6).

$D^{3}(T, t)=D_{0}^{3}+d . t$

In this equation, the parameter $d$ is thermally activated: $d=d_{0} \exp \left(\frac{-Q_{d}}{R T}\right) ; D$ is the grain size during sintering process during a duration $t$ at absolute temperature $T, D_{0}$ is the initial grain size, and $\mathrm{R}$ is the gas constant. $Q_{\mathrm{d}}$ is the apparent activation energy for grain growth.

Then a numerical solver ("GRG Nonlinear solver" implemented in Microsoft Excel, based on the Generalized Reduced Gradients method) is used to determine these parameters $\left(f_{\max }, f_{0}, n_{c}\right.$, $c_{0}, Q_{\mathrm{c}}, y_{0}, y_{\mathrm{dmax}}, n_{y}, s_{0}, Q_{\mathrm{s}}, D_{0}, d_{0}, Q_{\mathrm{d}}$ ), taking into account all steps of the sintering treatment; their optimized values are shown in table 5 . These calculations result in a good agreement between the calculated values of grain size, proportion of cubic phase and yttrium concentration in the tetragonal phase (obtained from the parameters in table 3) and their experimental values, as shown in Figure 9.

Table 5: Summary of the parameter of the microstructural models (equations (4) to (6)).

\begin{tabular}{cccccc}
\hline \multirow{2}{*}{ Cubic content } & $\boldsymbol{f}_{\max }$ & $\boldsymbol{n}_{\boldsymbol{c}}$ & $\boldsymbol{Q}_{\mathbf{c}}(\mathbf{k J} / \mathbf{m o l})$ & $\boldsymbol{c}_{\mathbf{0}}$ & $\boldsymbol{f}_{\mathbf{0}}$ \\
\cline { 2 - 6 } Mol. \% $\mathbf{Y}_{\mathbf{2}} \mathbf{O}_{\mathbf{3}}$ & 0.45 & 0.48 & 350.5 & $2.46 \cdot 10^{9}$ & 0.078 \\
(in t) & $\boldsymbol{y}_{\mathrm{d} \max }$ & $\boldsymbol{n}_{\boldsymbol{y}}$ & $\boldsymbol{Q}_{\mathrm{s}}(\mathbf{k J} / \mathbf{m o l})$ & $\boldsymbol{s}_{\mathbf{0}}$ & $\boldsymbol{y}_{\mathbf{0}}$ \\
\multirow{2}{*}{ Grain size (nm) } & 1 & 0.68 & 278.1 & $9.86 \cdot 10^{7}$ & 3.1 \\
& $\boldsymbol{D}_{\mathbf{0}}(\mathbf{n m})$ & $\boldsymbol{d}_{\mathbf{0}}\left(\mathbf{m}^{2} / \mathbf{s}\right)$ & $\boldsymbol{Q}_{\mathbf{d}}(\mathbf{k J} / \mathbf{m o l})$ & & \\
\hline
\end{tabular}



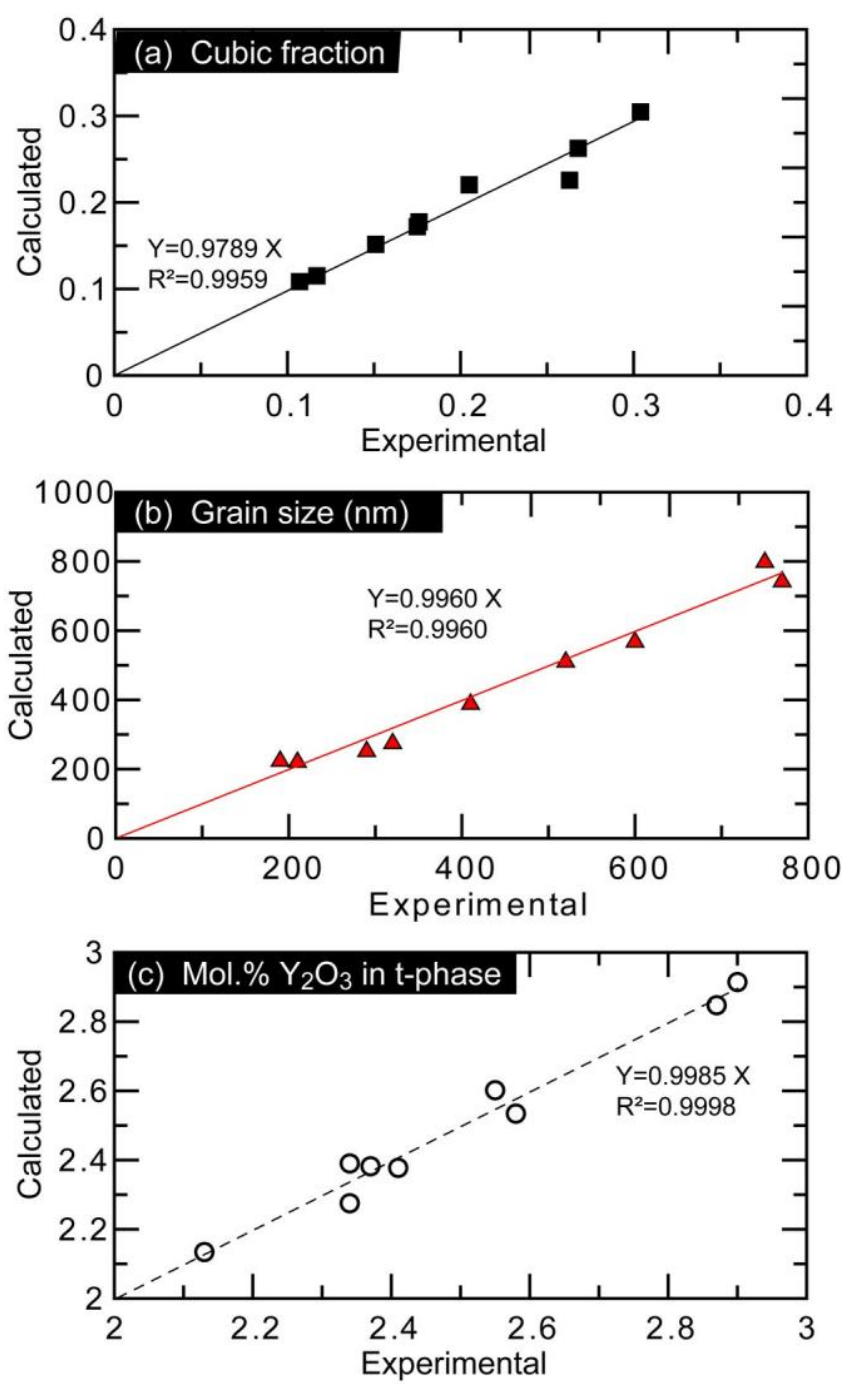

Figure 9: Comparison of the calculated and experimental values of $f, y, D$. Both the slopes of the trend lines and the $R^{2}$ values, close to 1 , show a good agreement between measured and calculate values.

\section{$\underline{4.2 \text { Prediction of ageing kinetics parameters from micro structural parameters }}$}

Activation energies for ageing (Q) between 41 and $117 \mathrm{~kJ} / \mathrm{mol}$ were found (table 4). Due to scattering of the measured monoclinic fraction data, it was decided that differences of less than $2 \mathrm{~kJ} / \mathrm{mol}$ were not significant, thus the average activation energy $(115.3 \pm 1.6 \mathrm{~kJ} / \mathrm{mol})$ of samples 1430-2h, 1430-5h, PS1430-20h, PS1500-2h and PS1550-2h was attributed to all these samples. The same argument applies for $n$, thus the average value of $n$ (0.92) was chosen for all samples. Finally the parameters $V_{\max }$ and $b_{0}$ were recalculated according to these new values of $\mathrm{n}$ and $\mathrm{Q}$ (Table 6).

Then a multiple regression analysis (equations (7) and (8)) was applied to calculate the evolutions of $\frac{\left.\mathrm{b}_{0}-<\mathrm{b}_{0}\right\rangle}{\sigma_{\mathrm{b} 0}}$ and $\frac{\mathrm{V}_{\max }-\left\langle\mathrm{V}_{\max }\right\rangle}{\sigma_{\mathrm{V}_{\max }}} \operatorname{versus}\left(\frac{f-<f\rangle}{\sigma_{f}}, \frac{y-<y\rangle}{\sigma_{y}}\right.$ and $\left.\frac{D-\langle D\rangle}{\sigma_{D}}\right)$ (here, $\langle x\rangle$ is the average value of $x$ and $\sigma_{x}$ is its standard deviation).

$\frac{\mathrm{b}_{0}-<\mathrm{b}_{0}>}{\sigma_{\mathrm{b} 0}}=a_{f}^{b} \cdot \frac{f-<f>}{\sigma_{f}}+a_{y}^{b} \cdot \frac{y-<y>}{\sigma_{y}}+a_{D}^{b} \cdot \frac{D-<D>}{\sigma_{D}}$

$\frac{\mathrm{V}_{\max }-<\mathrm{V}_{\max }>}{\sigma_{\mathrm{V}_{\max }}}=a_{f}^{V} \cdot \frac{f-<f>}{\sigma_{f}}+a_{y}^{V} \cdot \frac{y-<y>}{\sigma_{y}}+a_{D}^{V} \cdot \frac{D-<D>}{\sigma_{D}}$

This approach was attempted using measured values of $f, y$ and $D$ summarized in table 6 . The values of $a_{f}, a_{y}, a_{D}$ obtained are summarized in Table 7 , and the absolute value of these 
coefficients can reflect the degree of correlation of the corresponding parameters. The calculated evolutions of $\mathrm{V}_{\max }$ and $\mathrm{b}_{0}$ are summarized in Fig. 10.

In such a linear regression (that uses only standardized data) the highest coefficients indicate which variable are the ones with prominent importance. Accordingly, considering the results summarized in table $7 . \mathrm{b}_{0}$ mainly depends on the grain size and a bit less on the $\mathrm{Y}$ concentration inside the tetragonal grains, whereas $\mathrm{V}_{\max }$ mainly depends on the grain size and the amount of cubic phase.

Table 6: Summary of parameters of all samples sensitive to ageing (when necessary, $b_{0}$ and $V_{\max }$ were recalculated with $\mathrm{n}=0.92$ and $Q=115.3 \mathrm{~kJ} / \mathrm{mol}$ )

\begin{tabular}{|c|c|c|c|c|c|c|}
\hline Samples & $V \max$ & $\mathbf{b}_{0}$ & $\mathbf{Q}(\mathbf{k J} / \mathbf{m o l})$ & $\begin{array}{c}f: \\
\text { wt. } \% \\
\text { cubic }\end{array}$ & $\begin{array}{c}y: \\
\text { mol \% } \mathrm{Y}_{2} \mathrm{O}_{3} \\
\text { in } \mathrm{t}\end{array}$ & $\begin{array}{c}D: \\
\text { Grain size } \\
(\mathrm{nm}) \\
\end{array}$ \\
\hline $1430-2 \mathrm{~h}$ & 0.82 & $3.64 \cdot 10^{13}$ & 115.3 & 17.6 & 2.55 & 410 \\
\hline $1430-5 h$ & 0.8 & $3.01 \cdot 10^{13}$ & 115.3 & 20.5 & 2.41 & 520 \\
\hline PS1150-200h & 0.85 & $7.64 \cdot 10^{2}$ & 40.8 & 17.5 & 2.34 & 320 \\
\hline PS1430-20h & 0.77 & $4.43 \cdot 10^{13}$ & 115.3 & 30.4 & 2.13 & 750 \\
\hline PS1500-2h & 0.79 & $3.28 \cdot 10^{13}$ & 115.3 & 26.3 & 2.37 & 600 \\
\hline PS1550-2h & 0.78 & $4.75 \cdot 10^{13}$ & 115.3 & 26.8 & 2.34 & 770 \\
\hline
\end{tabular}

Table 7. Values of the coefficients $a_{f}, a_{v}, a_{D}$ in equations (7) and (8)

\begin{tabular}{|c|c|c|c|c|c|}
\hline & $a_{f}^{b}$ or $a_{f}^{v}$ & $\mathbf{a}_{\mathbf{y}}^{\mathbf{b}}$ or $\mathbf{a}_{\mathbf{y}} \mathbf{v}$ & $a_{D}^{b}$ or $a_{D}^{v}$ & $\begin{array}{l}\left\langle\mathbf{b}_{0}>\text { or }\right. \\
<V_{\text {max }}>\end{array}$ & $\begin{array}{l}\sigma_{\mathrm{b} 0} \text { or } \\
\sigma_{\mathrm{Vmax}}\end{array}$ \\
\hline$\frac{\mathbf{b}_{0}-<\mathbf{b}_{0}>}{\sigma_{\mathbf{b}_{0}}}$ & 0.12 & 0.57 & 1.05 & $3.18 \cdot 10^{13}$ & $1.70 \cdot 10^{13}$ \\
\hline$\frac{\mathbf{V}_{\text {max }}-<\mathbf{V}_{\text {max }}>}{\sigma_{V_{\text {max }}}}$ & -0.52 & -0.26 & -0.63 & 80.17 & 2.93 \\
\hline
\end{tabular}
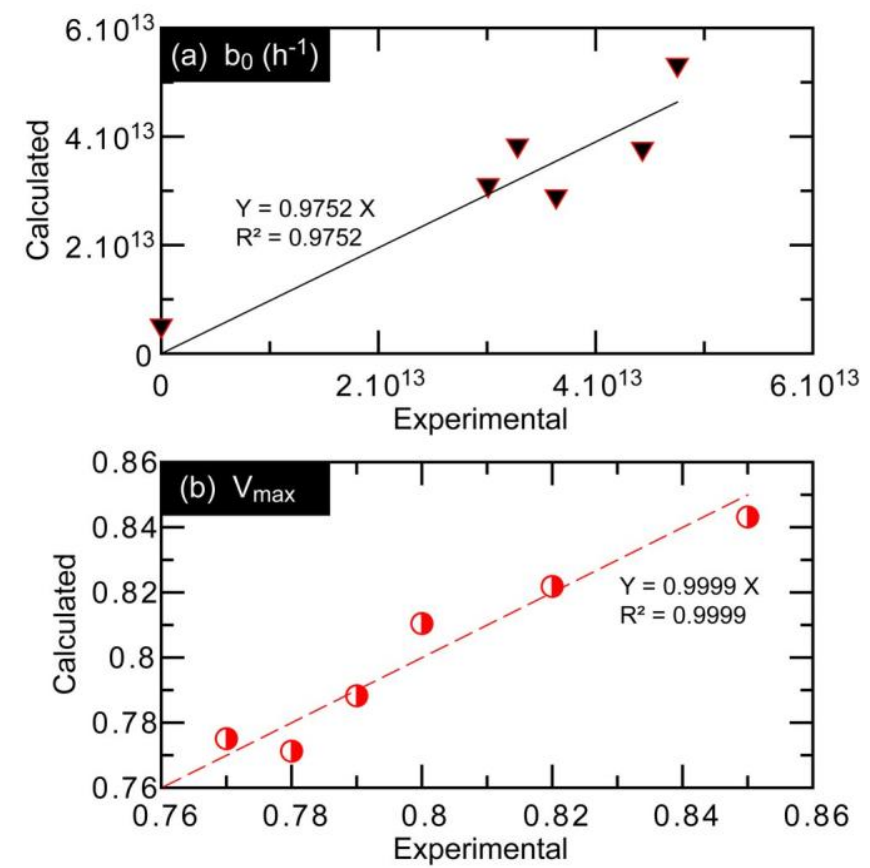

Figure 10: Comparison between experimental values of $b_{0}, V_{\max }$ and values of $b_{0}$ and $V_{\max }$ recalculated from the multiple regression analysis. 


\subsection{Predictive ability of the phenomenological models}

The models presented here (equations (4) to (8)) were established on a limited set of 9 materials obtained from a single powder. The question of their predictive power can thus be raised. To answer this, it can be interesting to compare their predictions to the microstructure and ageing kinetics of materials published by other authors [34-37].

An overall good agreement is found between the microstructural parameters measured by the different authors and the ones calculated by eq. (4) to (8) (see table 8 and figure 11 (a)). This is particularly true for grain size. However, discrepancies arise above $1600^{\circ} \mathrm{C}$ for Gremillard's materials: these materials (fabricated with a different powder: TZ3Y-S) exhibit a lower grain size than what is predicted by eq. (6). This could be attributed to the presence of a very small amount of amorphous phase at high temperature in TZ3YE, that can accelerate diffusion and grain growth as compared to amorphous-phase-free zirconia (such as TZ3YS). Between 1300 and $1600^{\circ} \mathrm{C}$, both powders behave similarly and excellent predictions can be reached by eq. (6).

Table 8: Summary of 3YTZP ceramics studied by other authors and comparison with values calculated using eq. 4 to 8. Experimental grain sizes, wt.\% cubic and mol/ $\mathrm{Y}_{2} \mathrm{O}_{3}$ in t. of materials from [34] and [35] were recalculated with the methods exposed in the present article, using the micrographs shown in [34] and [35] and the original XRD data kindly provided by Dr. Inokoshi and Dr. Zhang. These data are thus different from the published ones.

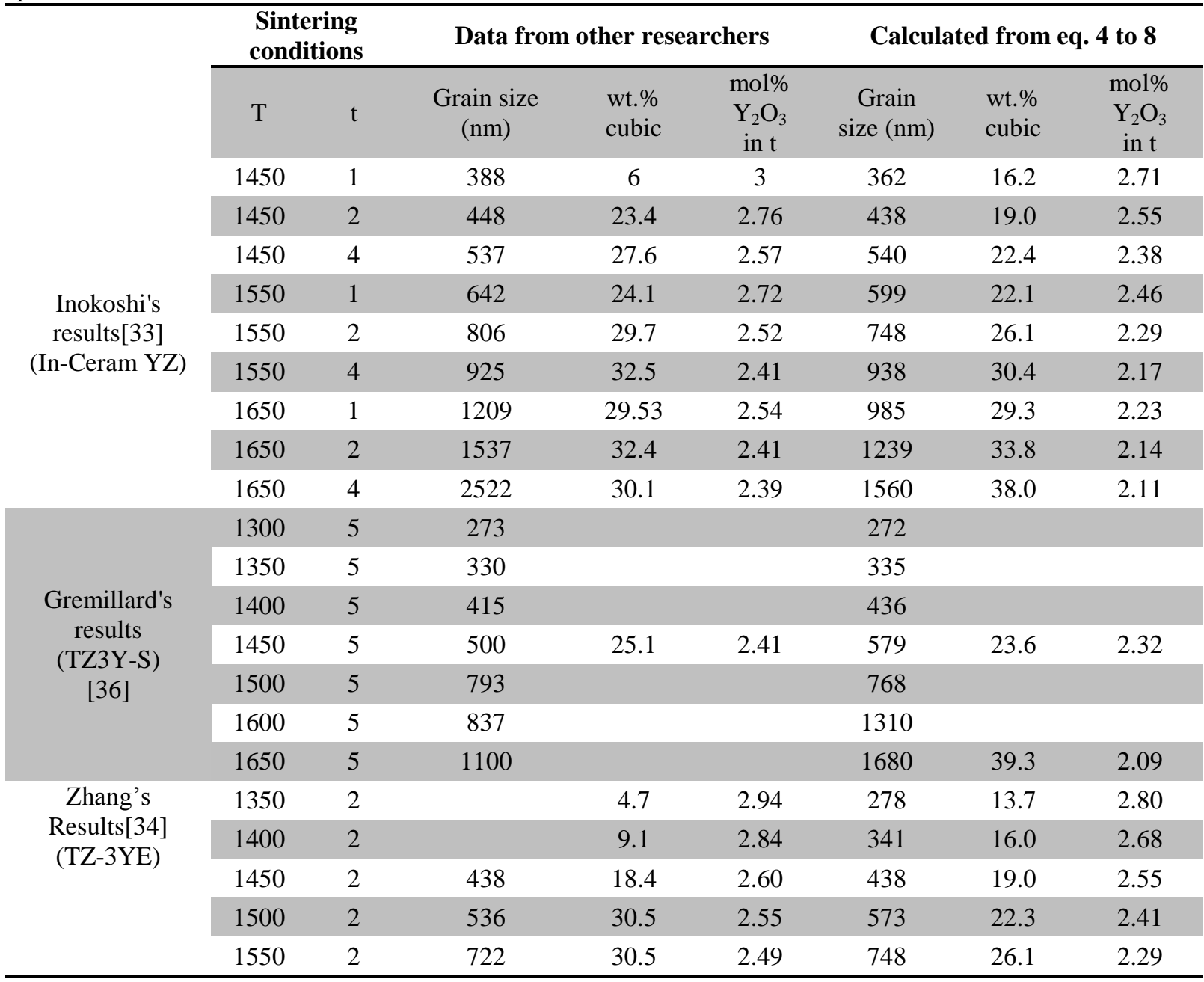


Even if the correlation is less good than for grain size, the proportion of cubic phase can be reasonably well predicted for all samples. However predictions for content of $\mathrm{Y}_{2} \mathrm{O}_{3}$ in tetragonal phase are not very good for Inokoshi's materials, which may be due in particular to the fact that the total amount of yttria inside these samples (based on Vita Inceram YZ) is not precisely known (the producer of Vita InCeram $\mathrm{YZ}$ guarantees a weight fraction of $\mathrm{Y}_{2} \mathrm{O}_{3}$ between 4 and $6 \%$, corresponding to a molar fraction between 2.2 and 3.6, thus this material may not be precisely a $3 \mathrm{Y}-\mathrm{TZP}$ ).
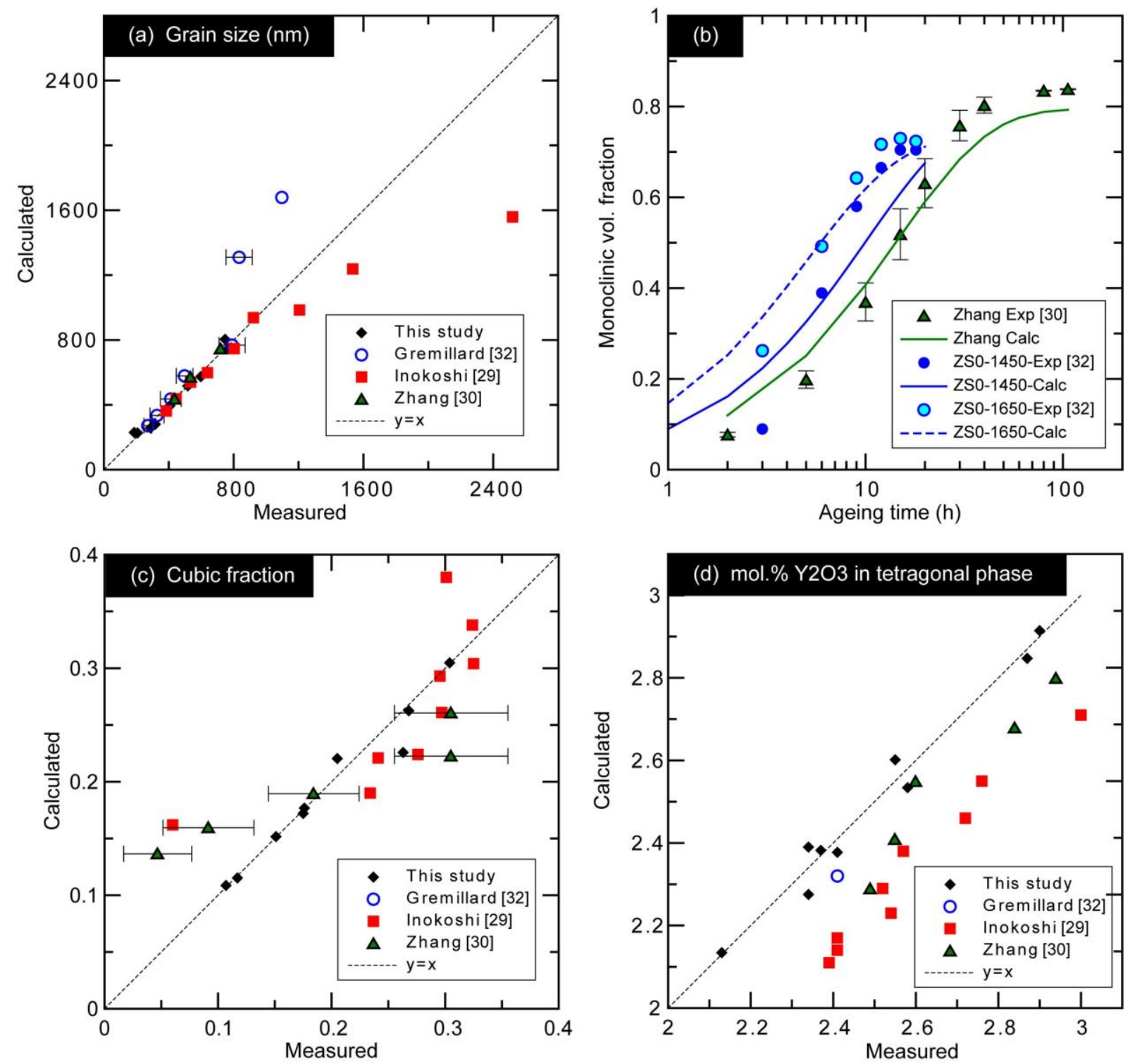

Figure 11: Comparison of the calculated and experimental values of several 3Y-TZP materials a) grain size, Inoshoki and Gremillard use other zirconia powders; b) Predicted surface phase transformation curves, compared with the experimental results of Zhang's TZ3YE sample [35] and Gremillard's TZ3YS samples [37]. Although the matches are not perfect, the orders of magnitude are correct and the ranking of samples is the same for the calculated ageing kinetics and the measured ones; (c) cubic fraction; (d) content of yttria in the cubic phase.

Fig.11 (b) shows ageing kinetics measured on three different materials at $134^{\circ} \mathrm{C}$, together with the ones calculated with a MAJ equation using $b_{0}$ and $V_{\max }$ extrapolated from the microstructural parameters by eq. (7) and (8) (and considering $\mathrm{Q}=115 \mathrm{~kJ} / \mathrm{mol}$ and $\mathrm{n}=0,92$ ). Here we need to point out that the Q value of these samples is reported to be about $106 \mathrm{~kJ} / \mathrm{mol}$ 
[9], while the predicted one is $115 \mathrm{~kJ} / \mathrm{mol}$. Being unable to calculate also $\mathrm{Q}$ and $\mathrm{n}$ from the microstructural parameters is clearly a limitation of our work. Even with this limitation in mind, the correlation between measured and calculated ageing kinetics is very good for Zhang's samples. It is less good for Gremillard's samples. Indeed for these samples the experimental kinetics exhibit a n value of 3.5 and 1 respectively for ZS0-1450 and ZS0-1600, much higher than the 0.92 used here. However the orders of magnitude are correct as well as the ranking among the materials.

Although these comparisons may be biased by factors that are not considered here (internal stresses, nature of the powder...), in all cases tested here the models give rather good approximations of the real microstructure and ageing behavior of 3Y-TZP materials.

\subsection{Influence of the microstructure on ageing kinetics of zirconia}

In general, decreasing grain size helps to enhance zirconia ageing resistance. Here this rule applies only at $134^{\circ} \mathrm{C}$, but is not systematically valid anymore at body temperature (see the example of PS1150-200 material). This is explained by a balance between $\mathrm{b}_{0}$ and Q. Many articles only focus on the study of Q [9] but ignore the changes in $b_{0}$, even though both reducing $b_{0}$ and increasing $Q$ can delay the ageing process at a given ageing temperature [4]. Here we show that each sample presents a unique combination of $\mathrm{b}_{0}$ and Q. TSS1 and TSS2 samples do not suffer from ageing (thus $\mathrm{b}_{0}$ and $\mathrm{Q}$ cannot be determined), PS1150-200h sample has the smallest $\mathrm{b}_{0}$ and Q among all samples, and samples 1430-2h, 1430-5h, PS143020h, PS1500-2h, PS1550-2h have Q around $115 \pm 2 \mathrm{~kJ} / \mathrm{mol}$. The differences between the last 5 samples seem to be related mostly to the grain size $\left(\mathrm{a}^{\mathrm{b}} \sim 1.1\right.$ is the highest coefficient in eq. 7 ) and (a little bit less) to the content of yttrium in the tetragonal phase $\left(\mathrm{a}_{\mathrm{y}}^{\mathrm{b}} \sim 0.57\right.$ is the second highest coefficient in eq.7), that directly influence its stability. Indeed, lower Y content in the tetragonal grains directly means less stable tetragonal phase. The effect of grain size is less easy to explain. At least two explanations are possible. The first one is that larger grain size leads to larger internal stresses and easier transformation. The second calls on the defect structure of grain boundaries. Indeed, considering Paul's experimental results [19], when the grain size becomes smaller, the specific surface area of grain boundaries becomes higher, as well as the number of oxygen vacancies $\left(\mathrm{Y} / \mathrm{Zr}-\mathrm{V}_{\ddot{\mathrm{O}}}\right)$ exposed to grain boundaries, and when their number increases to a certain extent, this leads to a dramatic change of $\mathrm{b}_{0}$ and $\mathrm{Q}$. This would also explain the difference between this group of 5 samples and PS1150-200h samples, that present the smallest grain size but similar percentage of yttrium in the $t$ phase.

Finally, this works lacks data on $\mathrm{Q}$ and $\mathrm{n}$. Indeed, activation energies for ageing found in the literature cover a 40 to $120 \mathrm{~kJ} / \mathrm{mol}$, however here only two groups (40 and 115) could be distinguished. As for $\mathrm{n}$, in the literature values between 0.5 and 4 were found, whereas here all values of $n$ are close to 1 . Thus one can deduce that grain size, amount of yttrium in the tetragonal phase and proportion of cubic phase do not influence $n$. Changes in $n$ (and $Q$ ) might then be related to other factors, such as perhaps the presence of internal and applied stresses or change in the chemistry of the zirconia powder. 


\section{Conclusions}

In this article, we provide a predictive, phenomenological model of the influence of sintering conditions on the microstructure (amount of cubic phase, yttria content in the different phases, average grain size) of 3Y-TZP ceramics, based on results obtained on nine 3Y-TZP materials fabricated from the same powder but with different sintering cycles and validated on materials fabricated by other authors.

Moreover, we propose another phenomenological model that can approximate rather precisely the ageing behavior of $3 \mathrm{Y}$-TZP materials (via the parameters $\mathrm{n}, \mathrm{Q}, \mathrm{V}_{\max }, \mathrm{V}_{0}$ and $\mathrm{b}_{0}$ of the MAJ law describing ageing kinetics), based on their microstructure. All materials in the present study presented a $\mathrm{n}$ value of 0.92 . From the model, it was deduced that $\mathrm{V}_{\max }$ has a strong linear relationship with both the content of cubic phase and the grain size. $b_{0}$ is closely linked with yttria content in the tetragonal phase and grain size.

Finally, it can be concluded that different powders can give different microstructures for a same sintering cycle. Since a strong relation was evidenced between ageing parameters and microstructural features, hydrothermal ageing of zirconia ceramics cannot always be predicted directly from processing parameters. However, it can be predicted from the microstructural features, independently of the powder used.

\section{Acknowledgments}

C. Wei was supported by a grant from the Chines Science Council.

The authors wish to thank Dr. Fei ZHANG and Dr. Masanao INOKOSHI (K.U. Leuven) for providing the data used to establish the comparisons shown in table 8 and figure 11.

\section{$\underline{\text { References }}$}

[1]R.C. Garvie, R.H.J. Hannink, R.T. Pascoe, Ceramic Steel?, Nature 258 (1975) 703-704

[2] J. Chevalier, What future for zirconia as a biomaterial?, Biomaterials 27 (2006) 535

[3] C. Piconi, G. Maccauro, Zirconia as a ceramic biomaterial, Biomaterials 20 (1999) 1-25

[4] J. Chevalier, L. Gremillard, A.V. Virkar, D.R. Clarke, The tetragonal-monoclinic transformation in zirconia: lessons learned and future trends, J. Am. Ceram. Soc, 92 (2009) 1901-1920

[5] L. Gremillard, S. Meille, J. Chevalier, J. Zhao, V. Fridrici, Ph. Kapsa, J. Gereinger, J. Uribe, Degradation of bioceramics, in N. Eliaz (ed), Degradation of Implant Materials, Springer, New York, 2012, 195-240

[6] X. Guo, Hydrothermal degradation mechanism of tetragonal zirconia, J. Mater. Sci. 36 (2001) 3737-3744

[7] H. Schubert, F. Frey, Stability of Y-TZP during hydrothermal treatment:neutron experiments and stability considerations, J. Eur. Ceram. Soc. 25 (2005) 1597-1602

[8] A. Gebressilassie, Atomic Scale Simulations in Zirconia: Effect of yttria doping and environment on stability of phases. Ph.D. Thesis, INSA-Lyon, France, 2016 
[9] J. Chevalier, B. Cales, J.M. Drouin, Low-Temperature Ageing of Y-TZP Ceramics; J. Am. Ceram. Soc. 82 (1999) 2150-2154

[10] L. Gremillard, J. Chevalier, T. Epicier, S. Deville, G. Fantozzi. Modeling the ageing kinetics of zirconia ceramics; J. Eur. Ceram. Soc. 24 (2004) 3483

[11]L. Gremillard, L. Martin, L. Zych, E. Crosnier, J. Chevalier, A. Charbouillot, P. Sainsot, J. Espinouse, J.-L. Aurelle, Combining ageing and wear to assess the durability of zirconiabased ceramic heads for total hip arthroplasty, Acta Biomaterialia 9 (2013) 7545-7555

[12] J. Chevalier, S. Deville, E. Munch, R. Jullian, F. Lair, Critical effect of cubic phase on ageing in $3 \mathrm{~mol} \%$ yttria-stabilized zirconia ceramics for hip replacement prosthesis, Biomaterials 25 (2004) 5539-45

[13] S. Deville, J. Chevalier, L. Gremillard, Influence of surface finish and residual stresses on the ageing sensitivity of biomedical grade zirconia, Biomaterials 27 (2006) 2186-2192

[14] L. Hallmann, A. Mehl, P. Ulmer, E. Reusser, J. Stadler, R. Zenobi, B. Stawarczyk, M. Özcan, C.H.F. Hämmerle, The influence of grain size on low-temperature degradationof dental zirconia, J. Biomed. Mater. Res. Part B 100 (2012) 447-456

[15] S. Schmauder, U. Schubert. Significance of internal stresses for the martensitic transformation in yttria-stabilized tetragonal zirconia polycrystals during degradation. J. Am. Ceram. Soc. 69 (1986) 534-40

[16] S. Deville, Etude des mécanismes de renforcement et de dégradation des céramiques biomédicales à base de zircone : du macroscopique au nanoscopique. Ph.D. Thesis, INSALyon, France, 2004

[17] J. Muñoz-Saldaña, H. Balmori-Ramirez, D. Jaramillo-Vigueras, T. Iga, G.A. Schneider. Mechanical properties and low-temperature ageing oftetragonal zirconia polycrystals processed by hot isostatic pressing. J. Mater. Res. 18 (2003) 2415-26

[18] S. R. Jansen, A. J. A. Winnubst, Y. J. He, H. Verweij, P. G. Th. van der Varst and G. de With, Effects of Grain Size and Ceria Addition onAgeing Behaviour and Tribological Properties of Y-TZP Ceramics, J. Eur. Ceram. Soc., 18 (1998) 557-563

[19] A. Paul, B.Vaidhyanathan, and J.G.P. Binner, Hydrothermal Ageing Behavior of Nanocrystalline Y-TZP Ceramics, J. Am. Ceram. Soc., 94 [7] (2011) 2146-2152

[20]S. Deville, G. Guenin, J. Chevalier. Martensitic transformation in zirconia - Part I. Nanometer scale prediction and measurement of transformation induced relief. Acta Mater. 52 [19] (2004) 5697-5707

[21] J. Eichler, J. Rödel, U. Eisele, M. Hoffman, Effect of grain size on mechanical properties of submicrometer 3Y-TZP: Fracture strength and hydrothermal degradation, J. Am. Cera. Soc. 90 [9] (2007) 2830-2836

[22] L. Ruiz, M. J. Readey, Effect of heat treatment on grain size, phase assemblage and mechanical properties of 3 mol\% Y-TZP, J. Am. Soc. 79 [9] (1996) 2331-2340

[23] D. Bucevac, T. Kosmac, A. Kocjan, The influence of yttrium-segregation-dependent phase partitioning and residual stresses on the aging and fracture behaviour of 3Y-TZP ceramics, Acta Biomater. (2017), in press, http://dx.doi.org/10.1016/j.actbio.2017.08.014 
[24] I.-Wei Chen and X.-H. Wang, Sintering dense nanocrystalline ceramics without finalstage grain growth, Nature 404 (2000) 168-171

[25] M. I. Mendelson, Average grain size in polcrystalline ceramics, J. Am. Ceram. Soc. 52 (1969) 443-446

[26] H. G. Scott. Phase relationships in the zirconia-yttria system. J. Mater. Sci. 10 (1975) 1527

[27] F.F. Lange, D.B. Marshall, J.R. Porter. Controlling microstructures through phase partitioning from metastable precursors: the $\mathrm{ZrO} 2-\mathrm{Y} 2 \mathrm{O} 3$ system. In J.D. MacKenzie, D.R. Ulrich (Eds.), Ultrastructure Processing of Advanced Ceramics, Wiley \& Sons, New York (1988) 519-532

[28] T. Stoto, M. Neuer, C. Carry, Influence of residual impurities on phase partitioning and grain growth processes of Y-TZP materials. J. Am. Ceram. Soc. 74 (1991) 2615-2621

[29] H. Toraya, M. Yoshimura, S. Somiya. Calibration curve for quantitative analysis of the monoclinic tetragonal ZrO2 system byX-rays diffraction. J. Am. Ceram. Soc. 67 (1984) 11921

[30] R.C. Garvie, P.S. Nicholson. Phase analysis in Zirconia systems. J. Am. Ceram. Soc. 55 (1972) 303-5

[31] L. Gremillard, C. Wei, J. Chevalier, K. Hans, T. Oberbach. A fast, stepwise procedure to assess time-temperature equivalence for hydrothermal ageing of zirconia-based materials, Journal of the European Ceramic Society (2017), http://dx.doi.org/10.1016/j.jeurceramsoc.2017.08.018

[32] K. Matsui, H. Horikoshi, N. Ohmichi, M. Ohgai, H. Yoshida, Y. Ikuhara, cubicformation and grain-growth mechanisms in tetragonal zirconia polycrystal, J. Am. Ceram. Soc. 86 [8] (2003) 1401-8

[33] K. Matsui, H. Yoshida, Y. Ikuhara, Isothermal Sintering Effects on Phase Separation and Grain Growth inYttria-Stabilized Tetragonal Zirconia Polycrystal. J. Am. Ceram. Soc., 92 [2] (2009) 467-475

[34] M. Inokoshi, F. Zhang, J. De Munck, S. Minakuchi, I. Naert, J. Vleugels, B. Van Meerbeek, K. Vanmeensel. Influence of sintering conditions on low-temperature degradation of dental zirconia. Dental materials 30 (2014) 669-678

[35] F. Zhang, K. Vanmeensel, M. Inokoshi, M. Batuk, J. Hadermann, B. Van Meerbeek, I. Naert, J. Vleugels. 3Y-TZP ceramics with improved hydrothermal degradation resistance and fracture toughness. J. Eur. Ceram. Soc., 34 [10] (2014) 2453-2463

[36] F. Zhang, K. Vanmeensel, M. Batuk, J. Hadermann, M. Inokoshi, B. Van Meerbeek, I. Naert, J. Vleugels. Highly-translucent, strong and ageing-resistant 3Y-TZP ceramics for dental restoration by grain boundary segregation. Acta Biomater., 16 (2015) 215-222

[37] L. Gremillard, Relations microstructure-durabilité dans une zircone biomédicale. $\mathrm{PhD}$ thesis, INSA-Lyon, France, 2002 